First publ. in: Journal of Experimental Zoology / Part B, Molecular and Developmental Evolution, 288 (2000), pp. 76-92

\title{
Total Evidence: Molecules, Morphology, and the Phylogenetics of Cichlid Fishes
}

\author{
IZENI P. FARIAS, ${ }^{1,2}$ GUILLERMO ORTÍ ${ }^{1 *}{ }^{*}$ AND AXEL MEYER ${ }^{3}$ \\ ${ }^{1}$ School of Biological Sciences, University of Nebraska, Lincoln, \\ Nebraska 68588-0118 \\ ${ }^{2}$ Departamento de Biologia, Instituto de Ciências Biológicas, Universidade \\ do Amazonas, 69077-000, Manaus, Amazonas, Brasil \\ ${ }^{3}$ Department of Biology, University of Konstanz, D-78457 Konstanz, Germany
}

\begin{abstract}
We present a most comprehensive phylogenetic analysis of the family Cichlidae. New data analyzed include mitochondrial 16S rRNA sequences and two nuclear loci (Tmo-M27 and Tmo-4C4) for a large taxonomic sampling with emphasis on South American species. We also incorporate a published morphological data set for a total evidence analysis. Character congruence among mitochondrial (74 taxa) and nuclear data (50 taxa) was high. However, partitionhomogeneity tests suggest significant heterogeneity among molecular and morphological data. In agreement with results obtained from molecular data alone, total evidence analysis (1,460 characters for 34 taxa) supports a robust phylogenetic hypothesis for the family Cichlidae that is congruent with drift-vicariance events associated with the fragmentation of Gondwana. Our analyses confirm the placement of Malagasy/Indian cichlids as the most basal lineages, with a sister-group relationship to the monophyletic African and Neotropical clades. Total evidence suggests that the controversial African genus Heterochromis is at the base of the African radiation. Among more than 50 Neotropical genera analyzed, Retroculus is identified as the basal taxon, with successive branching of Cichla, Astronotus, geophagines (including crenicichlines) + chaetobranchines, and cichlasomines + heroines. Relative rate tests applied to mitochondrial DNA suggest significantly higher rates of genetic variation in Neotropical than in African taxa, and both mitochondrial and nuclear sequences show that rate heterogeneity among Neotropical lineages is confined to the geophagine cichlids. J. Exp. Zool. (Mol. Dev. Evol.) 288:76-92, 2000. @ 2000 Wiley-Liss, Inc.
\end{abstract}

Cichlids (Cichlidae, Perciformes) have been used as model organisms to study a diversity of evolutionary trends such as parental care, mating systems, sexual selection, and functional morphology (see reference Keenleyside, '91, for reviews on cichlid biology). Their center of biodiversity is located in the East African Great Lakes (Victoria, Malawi, and Tanganyika), that harbor more than two-thirds of the estimated 2,000 species in the family. Speciation and adaptive radiations of cichlids evidently have been more pronounced in lacustrine than in riverine environments, probably facilitated by repeated isolation of subpopulations caused by historical fluctuations of the water level in these lakes (Sturmbauer, '98; Stiassny and Meyer, '99). Only 90-100 species live in African rivers (Greenwood, '91), about 18 species in Madagascar (Schmidt, '96), and three species live in southern India and Sri Lanka. Not surprisingly, most phylogenetic studies to date have focused on the African lacustrine cichlid radiations (e.g., Meyer, '93; Mayer et al., '98). In con- trast to African riverine environments, some 550 cichlid species live in rivers of the New World (Kullander, '98) and form an important element of the highly diverse Neotropical ichthyofauna. Despite being considerably less speciose than their relatives in African lakes, Neotropical cichlids are extremely varied in morphology, behavior, and ecology (Lowe-McConnell, '91). Endemism and trophic specialization also are relatively common and, to a certain extent, Neotropical cichlids replicate the African lacustrine evolutionary scenario, albeit at a smaller scale (Stiassny, '81). Here, we analyze character congruence among morphologi-

\footnotetext{
Grant sponsor: University of Nebraska-Lincoln (USA); Grant sponsor: Universidade Federal do Pará (Brazil); Grant sponsor: Universidade do Amazonas (Brazil); Grant sponsor: National Science Foundation; Grant number: DEB-9615178; Grant sponsor: the Deutsche Forschungsgemeinschaft; Grant sponsor: the Fond der Chemischen Industrie; Grant sponsor: University of Konstanz. *Correspondence to: Guillermo Ortí, School of Biological Sciences, 314 Manter Hall, University of Nebraska, Lincoln, NE 68588-0118. E-mail: gorti@biocomp.unl.edu

Received 4 October 1999; Accepted 27 December 1999
} 
cal data (Kullander, '98) and three molecular data sets (one mitochondrial and two nuclear genes) used to infer the phylogeny of cichlid fishes.

The practice of combining independent data sets into a single phylogenetic analysis continues to be debated in the recent literature (Bull et al., '93; Eernisse and Kluge, '93; Chippindale and Wiens, '94; Miyamoto and Fitch, '95; de Queiroz et al., '96; Ballard et al., '98; Kluge, '98). When data partitions are less heterogeneous than expected by sampling error alone, it is generally accepted (e.g., Bull et al., '93; Chippindale and Wiens, '94) that all data should be combined to obtain the best estimate of phylogeny. Tests for incongruence among data matrices (e.g., Rodrigo et al., '93; Farris et al., '94, '95) are increasingly used but consensus has yet to emerge regarding how to proceed in cases where significant heterogeneity is obtained. Many promising alternatives have been suggested recently (e.g., de Queiroz, '93; Chippindale and Wiens, '94; Kluge, '98; Wiens, '98). Additional meaningful outcomes derived from examination of incongruence among data partitions involve an increasing focus on the evolutionary forces underlying character variation among taxa (e.g., Canatella et al., '98) and assessment of phylogenetic utility of the characters used. Thus, procedures used to evaluate patterns of discordance among data partitions provide not only the basis for deciding how to best conduct phylogenetic analysis (whether to combine or how to combine), but also enlighten our understanding of the forces shaping character evolution.

Our phylogenetic study is mainly concerned with the South American cichlid radiation. Previous analyses of morphological traits have prompted the informal subdivision of Neotropical cichlids into several suprageneric groups: chaetobranchines, crenicichlines, geophagines, heroines, and cichlasomines. Stiassny ('91) suggested three unresolved alternatives for the interrelationship of these groups (her Fig. 1.5). More recently, Kullander ('98) published a fully resolved phylogeny and proposed a new classification for the family Cichlidae, especially for the South American genera, assigning new formal names to subfamilies and tribes (for more details see: www.nrm.se/ve/pisces/acara). An unanticipated outcome of this work was the inclusion of the enigmatic riverine genus Heterochromis (endemic from the Congo Basin) within an otherwise Neotropical clade (Kullander, '98). Most phylogenetic studies to date have consistently identified the major lineages of cichlids conforming to their current continental distributions, presumably due to drift-vicariance caused by late Cretaceous plate-tectonic events. Indian and Malagasy cichlids are considered basal taxa in the family, and form the sister group to the reciprocally monophyletic African and Neotropical clades (Stiassny, '91; Zardoya et al., '96; Streelman et al., '98; Farias et al., '99).

Molecular phylogenetic studies of the whole family Cichlidae have been somewhat hampered by the dearth of Neotropical taxa represented. Sültmann et al. ('95) sequenced anonymous nuclear DNA (DXTU1), Zardoya et al. ('96) microsatellite flanking regions (Tmo-M27), Streelman and Karl ('97) collected data from another single-copy nuclear (scn) DNA locus (Tmo-4C4), and Streelman et al. ('98) used both Tmo- scnDNA loci in a combined phylogenetic analysis. However, only two or three species included in these previous studies represented the entire Neotropical cichlid radiation of more than 500 species. Although Roe et al. ('97), and Martin and Bermingham ('98) carried out extensive taxonomic sampling of Central American heroines, South American genera remained poorly represented in their phylogeny of cytochrome $b$ sequences.

In a more comprehensive study, Farias et al. ('98, '99) sequenced a fragment of the mitochondrial (mt) 16S rRNA gene for 34 South American genera. They identified Neotropical cichlids as a monophyletic group and suggested that Heterochromis and Retroculus are the most basal taxa of their African and Neotropical clades, respectively. Although the scheme of relationships among Neotropical genera obtained by this study was highly resolved, the $16 \mathrm{~S}$ rRNA data (550 bp) provided but a single-locus estimate to confidently establish all relationships among South American and Old World cichlids (Farias et al., '99). In this paper we include all the previously available evidence and present phylogenetic results based on new 16S mtDNA and scnDNA (Tmo-M27 and Tmo-4C4) sequences for a comprehensive taxonomic sampling of Neotropical cichlids (about 35 additional taxa). We assess character congruence among molecular data sets and the morphological data published by Kullander ('98). Our main goal is to estimate relationships among the major groups of cichlids, with special emphasis on the South American radiation. We also examine rates and patterns of evolution in scnDNA and mtDNA sequences among the cichlid lineages. 


\section{MATERIALS AND METHODS \\ Taxon samples and DNA methods}

The fish taxa included in this study are listed in the Appendix. The locality and voucher specimen information for Neotropical cichlids is available from Izeni P. Farias. Suprageneric groups (e.g., cichlasomines, heroines, etc.) follow common usage and do not have formal systematic implications (Stiassny, '91). For a complete list of subfamily and tribe names of South American Cichlidae see Kullander ('98; or www.nrm.se/ve/pisces/acara). For all analyses the pomacentrid Abudefduf saxatilis and the embiotocid Damalichthys vacca were used as outgroups.

Total DNA was isolated from ethanol-preserved tissue by standard proteinase $\mathrm{K}$ digestion and phenol/chloroform extraction (Sambrook et al., '89). PCR amplifications for the nuclear loci Tmo-M27 and Tmo-4C4 followed conditions used by Zardoya et al. ('96) and Streelman and Karl ('97), respectively. The following internal primers (modified from Streelman and Karl, '97) were designed to amplify Tmo-4C4 for heroine cichlids: Tmo-4C4F2 5' CGGCCTTCCTAAAACCTCTCATTAAG 3' and Tmo-4C4-R2 5' GTGCTCCTGGGTGACAAAGTCTACAG 3'. Conditions used to amplify the 16S rRNA fragment followed Farias et al. ('99), using primers 16Sar and 16Sbr (Palumbi et al., '91). Double stranded PCR products were sequenced directly using the BigDye Terminator cycle sequencing ready reaction kit (Applied Biosystems Inc., Foster City, CA) on an automated DNA sequencer (Applied Biosystems 310) following manufacturer's instructions. The nucleotide sequence data determined for the present paper are deposited in GenBank (accession numbers: 165: AF045842-AF045865, AF048996-AF049019, AF112577-AF112597, AF112634-AF112642; TmoM27: AF112598-AF112633; Tmo-4C4: AF113060AF113095).

\section{Sequence alignment and phylogenetic analyses}

DNA sequences were aligned using CLUSTALW 1.5 (Thompson et al., '94). Settings for CLUSTALW were opening gap cost $=20$, extending gap cost $=5$. Each locus was aligned individually. For the Tmo-M27, only the regions flanking the microsatellite repeat were used for phylogenetic analysis, following Zardoya et al. ('96).

All phylogenetic analyses were performed using PAUP* version 4.0 b2a (Swofford, '98). Heuristic searches with 50 repetitions using random stepwise additions were performed under maximum parsimony (MP). For all analyses, transitions and transversions were weighted equally, and gaps were treated as "missing" data. Tree length (L), consistency indices (CI, excluding uninformative characters, Kluge and Farris, '69), and retention indices (RI, Farris, '89) are reported in each case. Minimum evolution (ME) methods (Kidd and Sgaramella-Zonta, '71) were also applied to the data, using maximum likelihood distances based on the HKY $+\mathrm{I}+\Gamma$ model (Hasegawa et al., '85; Yang, '93; Gu et al., '95). Parameters for this model (transition/transversion rate, proportion of invariable sites, and gamma shape parameter) were estimated by optimizing the data on the MP trees.

The level of confidence in each node of the MP and $\mathrm{ME}$ trees was assessed using non-parametric bootstrapping based on 100 pseudoreplicates (each with 10 random addition replicates). Bremer support (BS) values (Bremer, '88, '94) were used as additional measures of node stability under parsimony for the total evidence tree (see below). The number of extra steps required to collapse a given node was estimated for each clade of interest using constraint-trees constructed in MacClade 3.0 (Maddison and Maddison, '92). The most parsimonious topologies not satisfying a particular constraint were derived by heuristic searches with replicates (as before). Tree lengths from unconstrained trees are subtracted from tree lengths for constrained trees to determine BS for each node.

Previous analyses of $16 \mathrm{~S}$ rRNA sequences in cichlid fishes (Farias et al., '99) suggested heterogeneous rates of nucleotide change between Neotropical and African cichlids. The two-cluster test of Takezaki et al. ('95) was applied to gauge the effect of including additional African and Neotropical taxa in the present study (see Appendix). The test statistic ( $Z$ value) represents the deviation from zero of $\delta=L a-L b$, where $L a$ and $L b$ are the average number of observed substitutions per site (branch lengths), from the outgroup to the common ancestor of two monophyletic lineages $A$ and $B$, respectively. The test is implemented in the PHYLTEST program (Kumar, '96). Constancy of nucleotide substitution rates among Neotropical and African cichlids was tested using the Malagasy-Indian cichlids as outgroup. The basal position of these lineages among cichlids has been supported by morphological (Stiassny, '91) and several molecular data sets (Zardoya et al., '96; Streelman et al., '98). In order to minimize the effect of non-independence among distances, a 
single representative of each Neotropical genus was used when more than one species per genus was available. Relative rate tests are both more accurate and more powerful when only the nearest outgroup sequence is used rather than when all available outgroup sequences are used (Robinson et al., '98). In the present study, the single-nearest outgroup sequence used was Oxylapia for the16S data and Etroplus for nuclear loci and the combined molecular data sets. When the relative rate test was applied only to the Neotropical lineages, the African genus Heterochromis was used as outgroup. For each test, new alignments were performed and the model parameters estimated.

\section{Data partitions}

The present study involved the following sets of analyses. The first set included separate analysis for mitochondrial (16S) and nuclear loci (Tmo-M27, Tmo-4C4). The second set included a combination of both, mitochondrial and nuclear sequences (total molecular evidence). In the third series of analyses the molecular data (16S + nuclear loci) were combined with morphological data (see Kullander, '98, for matrix and list of characters) to reveal the phylogenetic pattern that is supported by total evidence analysis. Since data for all partitions were not available for all taxa, the taxonomic composition of each series of analysis is, by necessity, somewhat different.

Following Bull et al. ('93), we first analyzed the different data sets separately and then tested for heterogeneity between data partitions, before combining the data in a total evidence analysis. A simple test, the incongruence length difference (ILD) test, described by Farris et al. ('94, '95) measures the significance of incongruence among data sets. This test, also known as the partition-homogeneity test, is implemented in PAUP* $4.0 \mathrm{~b} 2 \mathrm{a}$ (Swofford, '98). The question of whether "to combine or not to combine" data sets for phylogenetic analysis remains controversial (Bull et al., '93; Eernisse and Kluge, '93; Chippindale and Wiens, '94; Miyamoto and Fitch, '95; Huelsenbeck et al., '96; de Queiroz et al., '96; Cunningham, '97; Ballard et al., '98; Kluge, '98). We adopt the position that data sets should be analyzed both separately and combined simultaneously to potentially increase the descriptive efficiency and explanatory power of the data (Eernisse and Kluge, '93). We agree with Liu and Miyamoto ('99) that the heterogeneity test "should not be used to justify automatically the continued separation of character partitions, rather these tests should be used to assess the distribution, nature, and extent of conflict among data sets."

\section{RESULTS}

\section{Patterns of nucleotide divergence}

We sequenced the 16S rRNA fragment for 74 taxa. The inclusion of six new African and Neotropical taxa in the present study (see Appendix) did not affect the patterns of nucleotide divergence obtained in our previous study (Farias et al., '99). The final alignment of 16S rRNA sequences resulted in $562 \mathrm{bp}$, of which 276 characters were variable and 206 were phylogenetically informative under parsimony. The mean base composition was the same as observed before (Farias et al., '99), and other estimated parameters were very similar to previous results (the transition/ transversion ratio was 2.42 , the proportion of variable sites $=0.34$ and gamma shape $=0.50$ ). The maximum pairwise divergence value observed among all taxa was 0.20 (uncorrected " $p$ " distance) between Teleocichla centrarchus and Paretroplus polyactis. On average, the number of changes per site was 2.8.

Both Tmo-M27 and Tmo-4C4 are suspected to be protein-coding DNA sequences (Streelman et al., '98). According to Streelman et al., ('98) the Tmo-M27 nucleotide sequence shows significant matches to RAS-specific guanine nucleotide-releasing factor (RAS-GRF). They also found that Tmo-4C4 polypeptide sequence revealed high similarity to several regions of TITIN and TITIN-like proteins believed to be related to immunoglobulin (IG) domains, which increase the elasticity of muscle contraction. In the present work, both Tmo-M27 (302 bp) and Tmo-4C4 (511 bp) sequences combined resulted in a total of $813 \mathrm{bp}$, of which 400 bp were variable and 250 bp phylogenetically informative under parsimony. The mean base composition was $28 \% \mathrm{~A}, 26 \% \mathrm{~T}, 27 \% \mathrm{G}$, and $19 \% \mathrm{C}$. The transition/transversion ratio was 3.19 , an evident bias in favor of transitions. Other parameters estimated were proportion of invariable sites $=0.17$ and gamma shape $=0.72$. From a total of 50 taxa included in the present work, 36 new taxa were sequenced for both nuclear loci. The maximum pairwise divergence value observed among all taxa was 0.21 (uncorrected " $p$ " distance) between Damalichtys vacca and Hemichromis bimaculatus. The average number of changes per site for the combined nuclear data set was 1.1 (0.9 for Tmo-M27 and 1.4 for Tmo-4C4). 
The combined molecular data set comprised a total of $1,371 \mathrm{bp}$ for 48 taxa (558 bp of 16S rRNA and $813 \mathrm{bp}$ of Tmo-M27 and Tmo-4C4). Of 653 variable characters, 432 were phylogenetically informative under parsimony. The estimated transition/transversion ratio was 2.70 . The other parameters estimated for the $\mathrm{HKY}+\mathrm{I}+\Gamma$ model were proportion of invariable sites $=0.29$ and gamma shape $=0.54$.

\section{Phylogenetic analyses}

\section{S rRNA mitochondrial gene}

The parsimony analyses of the 16S rRNA data resulted in three equally parsimonious trees $(\mathrm{L}=$ $1,566, \mathrm{CI}=0.305, \mathrm{RI}=0.594)$. Differences among the three MP trees involve relationships within the heroine and cichlasomine clades. ME resulted in a single tree (score $=2.60$, Fig. 1). These topologies are consistent with our previous findings (Farias et al., '99), and support the monophyly of the Cichlidae, the monophyly of the African and Neotropical cichlids, and the basal position and paraphyly of Malagasy/Indian cichlids. The main differences among MP and ME trees involve the placement of the chaetobranchines, and the relationships among some African taxa.

\section{Nuclear loci}

The partition-homogeneity test did not show significant heterogeneity $(P=0.86)$ among the nuclear gene fragments (Table 1), and thus both were combined for further analyses. Phylogenetic analysis of 48 cichlid taxa, based only on the nuclear loci (Tmo-M27 and Tmo-4C4), resulted in 76 equally parsimonious trees $(\mathrm{L}=877, \mathrm{CI}=$ $0.566, \mathrm{RI}=0.711$ ) a strict consensus of which is shown in Figure 2. This tree is similar to the trees obtained by Zardoya et al. ('96) and Streelman et al. ('98) in their analyses of nuclear genes, and shows that African and Neotropical cichlids form distinct monophyletic clades supported by $67 \%$ and $99 \%$ bootstrap values, respectively. The combined nuclear loci did not provide sufficient phylogenetic information to confidently resolve all relationships among South American cichlids. However, important taxonomic congruence with respect to the mtDNA tree (Fig. 1 and Farias et al., '99) includes: (1) Heterochromis is the most basal genus included in a monophyletic African clade; (2) in the Neotropical lineage, Retroculus is the most basal genus; (3) the geophagines, including crenicichlines (Crenicichla and Teleocichla), form a monophyletic group strongly supported by bootstrap value of $91 \%$; (4) cichlasomines and heroines are sister groups; and (5) Acaronia is placed among cichlasomines.

\section{Total molecular evidence}

As expected from the overall taxonomic congruence among nuclear and mtDNA phylogenies (Figs. 1 and 2), the partition-homogeneity test indicated no significant heterogeneity among the data partitions (Table 1). The combined molecular evidence for 46 cichlid taxa resulted in 12 equally parsimonious trees $(\mathrm{L}=2,032, \mathrm{CI}=0.446$, $\mathrm{RI}=0.601$ ). A strict consensus of these trees shows a trichotomy involving Astronotus, the geophagine+chaetobranchine clade, and the heroinecichlasomine clade. The ME analysis resulted in a single tree (score $=1.41$, Fig. 3 ). The topology and bootstrap values supporting the MP and ME trees are highly congruent (Fig. 3), and in agreement with the separate analyses (Figs. 1 and 2). The Cichlidae is monophyletic, the Malagasy/Indian cichlids are the most basal group in the family, and the African and Neotropical cichlids are monophyletic and sister groups. Relationships among African cichlids are consistent in placing Heterochromis as the most basal African taxon followed by the other West-African lineages Tylochromis and Hemichromis. In both MP and ME trees (Fig. 3), African monophyly is supported by $86 \%$ and $90 \%$ bootstrap values, respectively. Among Neotropical cichlids, Retroculus is identified as the most basal genus together with Cichla and Astronotus. The reciprocal monophyly of cichlasomines, heroines, and geophagines is well supported by the combined data. A close relationship between chaetobranchines (Chaetobranchus+ Chaetobranchopsis) and geophagines was found in all analyses and supported by bootstrap values of $79 \%$ and $75 \%$ in MP and ME trees (Fig. 3).

\section{Total evidence}

The partition-homogeneity test (Table 1) showed significant heterogeneity levels in the comparison between molecular and morphological data $(P \leq$ $0.01)$. This result was obtained in the face of a comparatively small number of informative morphological characters with regard to the molecular data. Cunningham ('97) applied different statistical tests to explore the relationship between incongruence and phylogenetic accuracy. He found that with heterogeneity values $P \geq 0.01$, combining data might still improve phylogenetic accuracy, and only with $P$ values $\leq 0.01$ a com- 


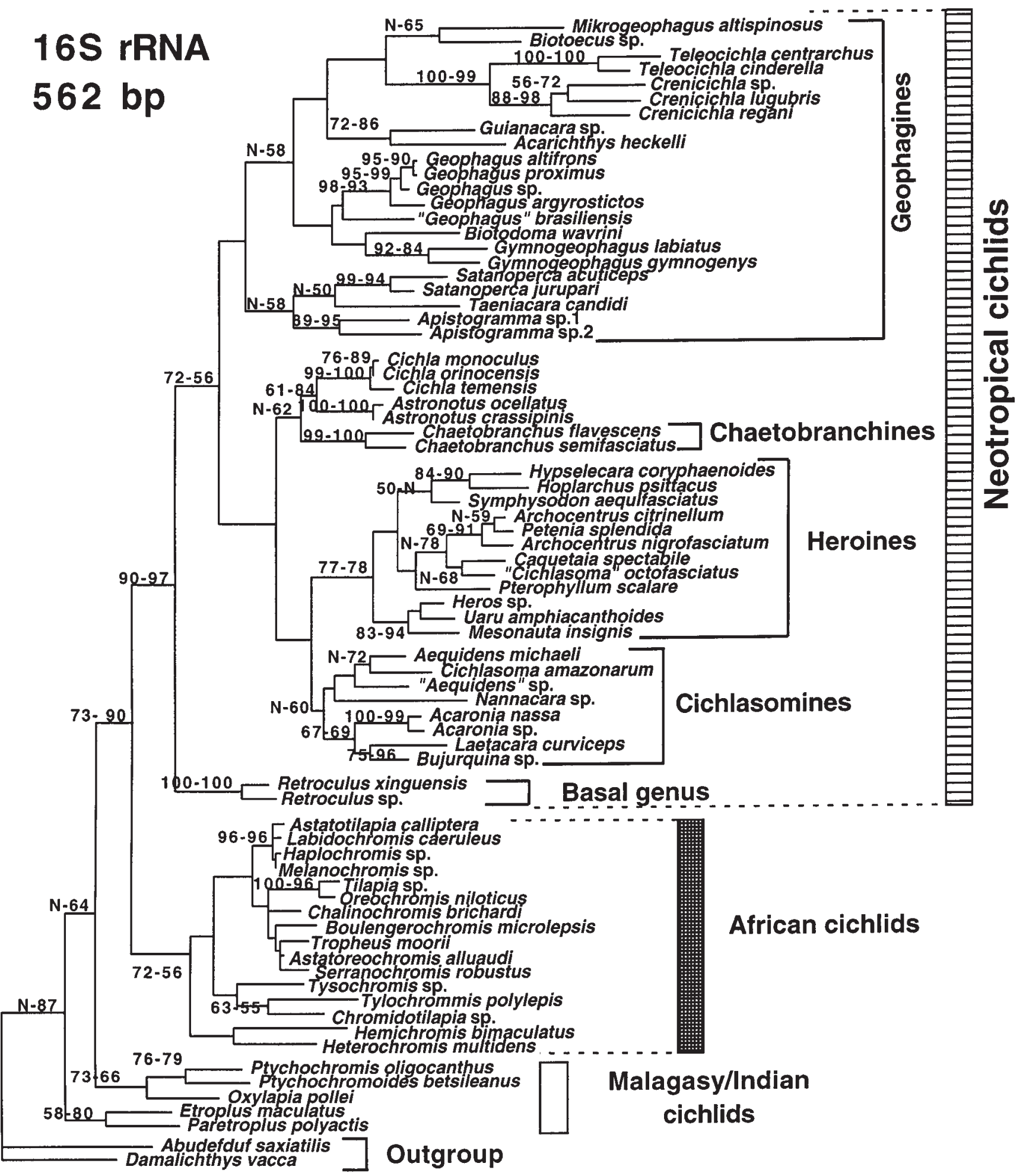

Fig. 1. ME tree based on 16S rRNA data obtained using $\mathrm{HKY}+\mathrm{I}+\Gamma$ distances $(\mathrm{ME}$ score $=2.60$, Tratio $=2.42$, Pinvar $=$ 0.34 , gamma shape $=0.50$ ). Numbers above branches are bootthe left and right of the branches are bootstrap values for $\mathrm{MP}$ and $\mathrm{ME}$, respectively. $\mathrm{N}$ indicates a bootstrap value bestrap values (only values above 50 are shown). Numbers on low $50 \%$ for either MP or ME. 
TABLE 1. P values for partition-homogeneity tests ${ }^{1}$

\begin{tabular}{lc}
\hline Comparisons & $P$ values \\
\hline Tmo-M27 × Tmo-4C4 loci & 0.86 \\
16S rRNA × nuclear loci & 0.04 \\
16S rRNA × morphological data & $0.01^{*}$ \\
Nuclear loci $\times$ morphological data & $0.01^{*}$ \\
Molecular data $\times$ morphological data & $0.01^{*}$ \\
\hline${ }^{1}$ 100 random replicates. & \\
*Significant heterogeneity at the 99\% confidence level. &
\end{tabular}

bined data matrix may be less accurate than individual data partitions. We follow Cunningham ('97) and Sullivan ('96) in considering a significance threshold of 0.05 to be too conservative for the homogeneity test. Furthermore, combining data sets may still be advantageous despite high levels of character incongruency, since the overall accuracy of the combined data may be increased by a larger number of characters applied to parts of the tree unaffected by the mismatch (Wiens, '98). Furthermore, by exploring taxon sampling in relation to heterogeneity tests, we attempt to identify the portions of the tree most affected by character incongruence (see Discussion).

All molecular and morphological character data available were subsequently combined for a total evidence analysis (16S + nuclear loci + morphological data; 1,460 characters for 34 taxa). Figure 4 shows a strict consensus tree of three equally parsimonious trees obtained $(\mathrm{L}=2,155$, CI $=$ $0.368, \mathrm{RI}=0.485$ ). Differences among the MP trees only involved the placement of Heros, Uaru, and Mesonauta within heroines. The combined data set provided increased resolution and higher bootstrap support compared to any of the individual data partitions. In agreement with our previous results, total evidence clearly shows that African and Neotropical cichlids are distinct monophyletic clades supported by bootstrap values of $92 \%$ and $100 \%$ and $\mathrm{BS}$ values of 8 and 15, respectively. Etroplus is placed as the most basal cichlid and Heterochromis is placed as the basal lineage of the African clade followed by Tylochromis.

Among the Neotropical cichlids, Retroculus is the most basal genus followed by Cichla and Astronotus. Two major lineages are observed, one formed by the cichlasomine and heroine groups and a second by the chaetobranchine and geophagine groups. The monophyly of cichlasomines is supported by a bootstrap value of $84 \%$ and $\mathrm{BS}$ value of 4 . The relationships among genera were the same as observed in all analyses. Bootstrap values of $89 \%$ and $\mathrm{BS}$ values of 4 supported the monophyly of heroines. Our analysis showed a close relationship among Heros, Uaru, Mesonauta, Symphysodon, and Pterophyllum, as was suggested by Kullander ('83) and Cichoki ('76). Among taxa included in this study, the basal position within heroines is occupied by the HypselecaraHoplarchus clade. The geophagines are a monophyletic group that includes crenicichlines, with bootstrap values of $93 \%$ and BS values of 9 . Despite low bootstrap values, chaetobranchines are closely related to geophagines in all analyses.

In conclusion, for the Neotropical assemblage, the total evidence results confirm: (1) the placement of Retroculus, Cichla, and Astronotus as basal lineages. In contrast to Stiassny ('91) and Kullander ('98) Cichla is not closely related to crenicichlines; (2) the monophyly of sister groups heroines and cichlasomines, with Acaronia included in the cichlasomine group; (3) the monophyly of geophagines including the crenicichline group; and (4) the close relationship among chaetobranchines and geophagines.

\section{Rates of molecular evolution}

The 16S rRNA data resulted in evident differences in branch lengths in the ME tree (Fig. 1). As reported by Farias et al. ('99), higher rates of evolution in Neotropical lineages, and in particular among geophagine cichlids, were detected based on the distribution of the genetic distances (Table 2). The relative rate test Z-statistic ( $\mathrm{Z}=$ 4.1342) rejected rate constancy $(P<0.05)$ among Neotropical and African lineages, showing that the average distance among lineages was significantly different in both continental faunas. Even when the geophagine group was excluded from the Neotropical clade, the average rate of substitution among Neotropical and African cichlids was significantly different $(\mathrm{Z}=2.5661)$. Only when lacustrine cichlids (short branch lengths) in Africa and the geophagines (long branch lengths) were excluded the relative rate test was non-significant (Table 2). The relative rate test applied only to the Neotropical clade showed significantly different rates among geophagines compared with the rest of the Neotropical taxa $(\mathrm{Z}=2.7996, P<0.05)$.

A separate analysis using $16 \mathrm{~S}$ rRNA data performed only on Old World cichlids confirmed a difference in the branch lengths of some lineages among African taxa in the ME tree (Fig. 1). An unrooted tree (obtained by $\mathrm{ME}$, result not shown) suggested that long branches are found mainly in the basal riverine African cichlids and also in some taxa from Lake Tanganyika. A relative rate 


\section{Nuclear Genes}
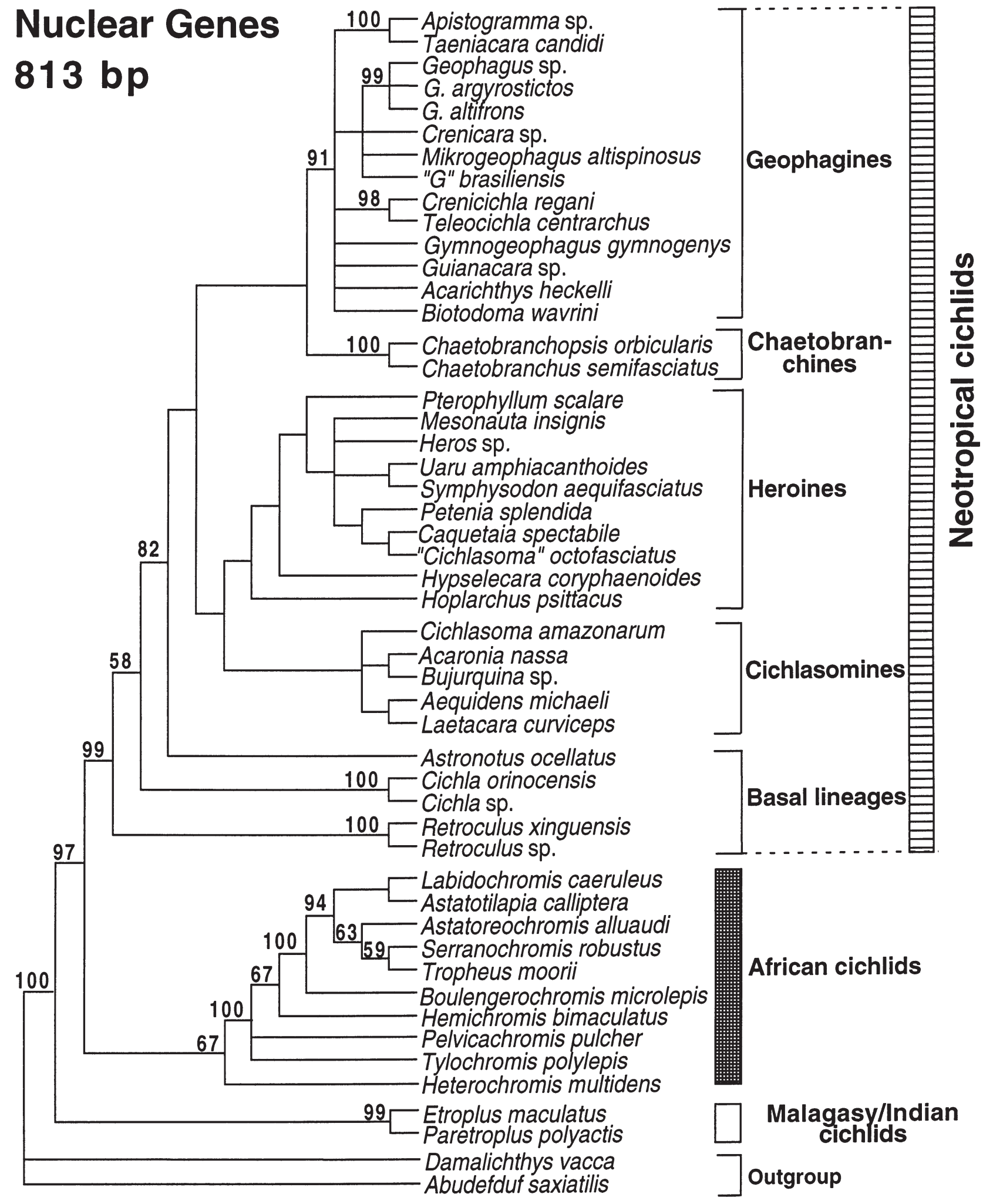

Fig. 2. Strict consensus of $76 \mathrm{MP}$ trees from nuclear loci data (Tmo-M27 + Tmo-4C4) $(\mathrm{L}=877, \mathrm{CI}=0.566, \mathrm{RI}=0.711)$.

Numbers above branches are bootstrap values (only values above $50 \%$ are shown). 


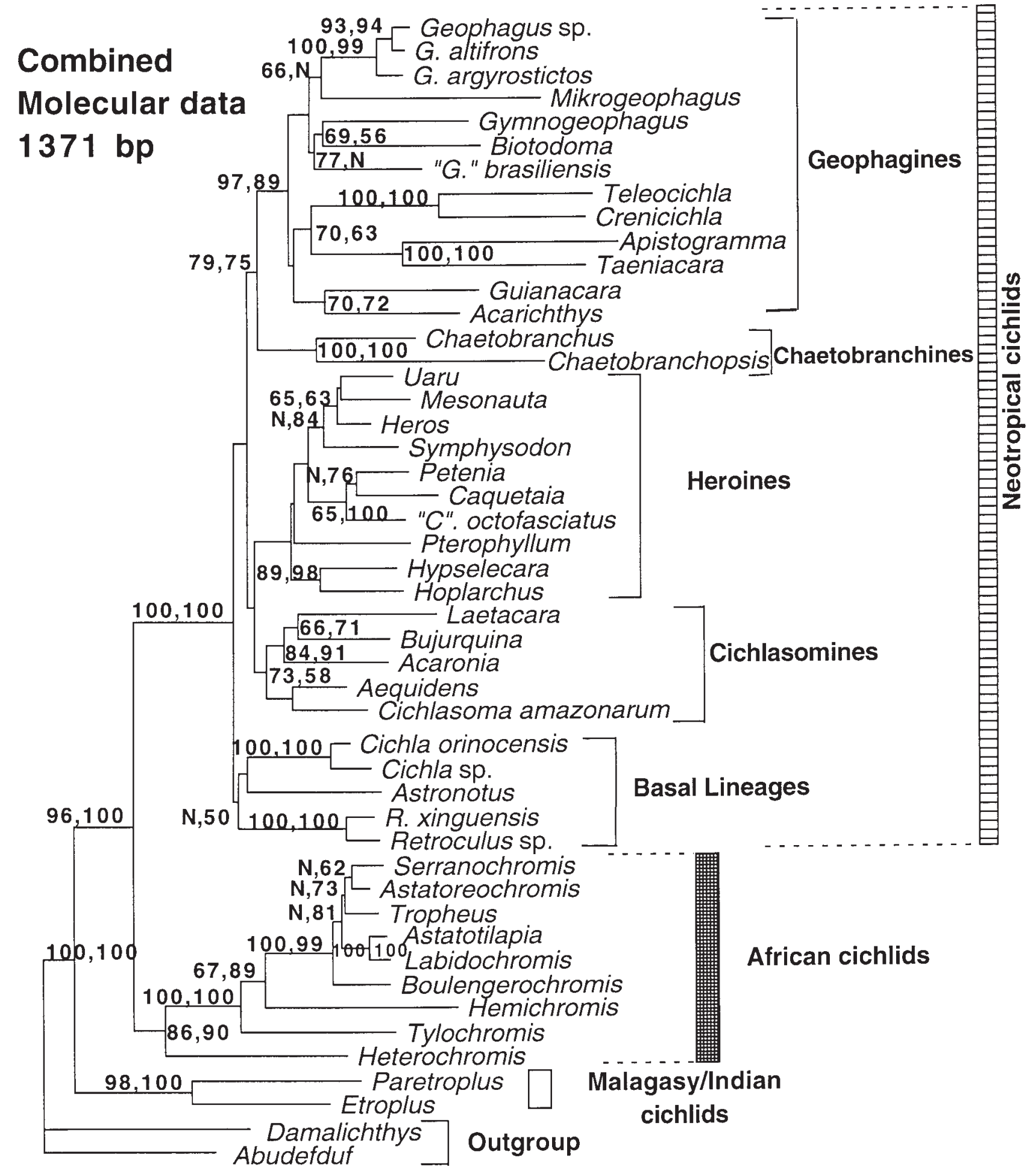

Fig. 3. ME tree from total molecular evidence (16S rRNA + nuclear loci) obtained using $\mathrm{HKY}+\mathrm{I}+\Gamma$ distances (score = 1.41 , Tratio $=2.70$, Pinvar $=0.29$ ). Numbers on the left and right of the branches are bootstrap values for MP and ME (only values above $50 \%$ are shown). $\mathrm{N}$ indicates values below $50 \%$ for either MP or ME tree. 
test among riverine and lacustrine African cichlids (with Oxilapia as outgroup) was performed (Table 2 ). The analysis revealed a surprising difference in branch lengths between riverine $(\mathrm{La}=0.0618)$ and lacustrine $(\mathrm{Lb}=0.0315)$ cichlids, rejecting rate constancy $(P<0.05)$ with a significant average distance value $(\mathrm{Z}=2.8521)$.

Despite observing considerable difference in branch lengths in the ME tree based on the TmoM27 data and smaller differences in the Tmo-4C4 tree (results not shown), significant heterogeneity was not detected between Neotropical and African cichlids for nuclear loci (Table 2). However, when the test was applied only to the Neotropical assemblage, Tmo-4C4 data showed significant differences $(P<0.05)$ among geophagines and the rest of the Neotropical taxa, confirming rate heterogeneity in both mitochondrial and nuclear DNA among the Neotropical lineages.

\section{DISCUSSION}

\section{Taxonomic and character congruence}

In a vast majority of studies, data from single mitochondrial genes are used to address systematic questions. However, single-gene reconstructions may lead to inconclusive discrimination of species trees among gene trees (Moore, '95). Only if one or more nuclear genes independently resolve the same topology as mtDNA, inference of the species tree rather than gene trees is strongly corroborated. Congruence among different data partitions has arguably provided the strongest evidence that a particular phylogenetic estimate is accurate (Penny and Hendy, '86; Swofford, '91). Comparison of Figures 1-4 shows that the concordant topologies obtained for the major lineages of cichlids in the present work are likely to be a reflection of organismal phylogeny rather than simply gene genealogies. Our phylogenetic analyses of mitochondrial (16S rRNA) and nuclear loci (Tmo-M27, Tmo-4C4) combined with morphology (from Kullander, '98) constitutes the most complete phylogenetic analysis of South American cichlids to date.

Our major systematic findings are compared to Kullander's ('98) hypothesis in Figure 5. Major discordance between the morphological and the total evidence results involve the relationships of Heterochromis, Cichla, Crenicichla, Chaetobranchus, and Acaronia. To gauge the effect of taxon sampling on the assessment of character incongruence, these taxa were removed individually and in all possible combinations, for additional partition-homogeneity tests of molecular and morphological subsets, using the 34taxon total evidence data set. Removal of these taxa individually did not result in change of $P$ value (for all tests $P=0.01$ ). Higher $P$ values were observed only when we removed two or more taxa, but never was $P>0.06$ for any combination. The largest change was obtained by the simultaneous removal of Heterochromis, Acaronia, and Crenicichla and by these three plus Cichla (for both cases $P=0.052$, with 500 replications). Given that these four taxa alone account for the major taxonomic discordance among morphological and molecular trees while all other aspects of the phylogeny are mostly congruent, it seems justified to set higher stringency standards (i.e., $P<$ 0.01 or smaller) to determine significant levels of character incongruency using partition-homogeneity tests, as suggested by Cunningham ('97) and Sullivan ('96).

Phylogenetic placement of the African genus Heterochromis (subfamily Heterochromidinae) among the basal lineages of the Neotropical clade (Fig. 5) is not supported by molecular data. Based on 16S rRNA sequences alone, Farias et al. ('99) suggested that Heterochromis constitutes a basal branch of the African clade, an observation supported by additional taxa and multilocus information presented here. Kullander ('98) placed Heterochromis among Neotropical cichlids (see Fig. 5) based on the following three morphological characters: (i) short anterior arm of epibranchial 1 (his character 2); (ii) interdigitating suture between the vomerine shaft and the parasphenoid bar (his character 37); and (iii) anterior palatoethmoid ligament present (his character 57). Our results, supported by total evidence, suggest that these morphological characters shared among Heterochromis and Neotropical cichlids may have originated independently. Homoplasious phenotypes attest to the strength of selection or, alternatively, internal constraints to sculpt similar phenotypes in response to similar selection pressures and to re-express ancient, retained, developmental programs (Meyer, '99). Quicke and Belshaw ('99) demonstrated eloquently how convergence among certain morphological characters resulting from a shared life history strategy may result in misleading phylogenetic reconstruction of the evolution of endoparasitism among braconid wasps. Stiassny ('92) used the family Cichlidae as one example to suggest that much character incongruence present in morphological evolution is the result of taxic atavism (a 


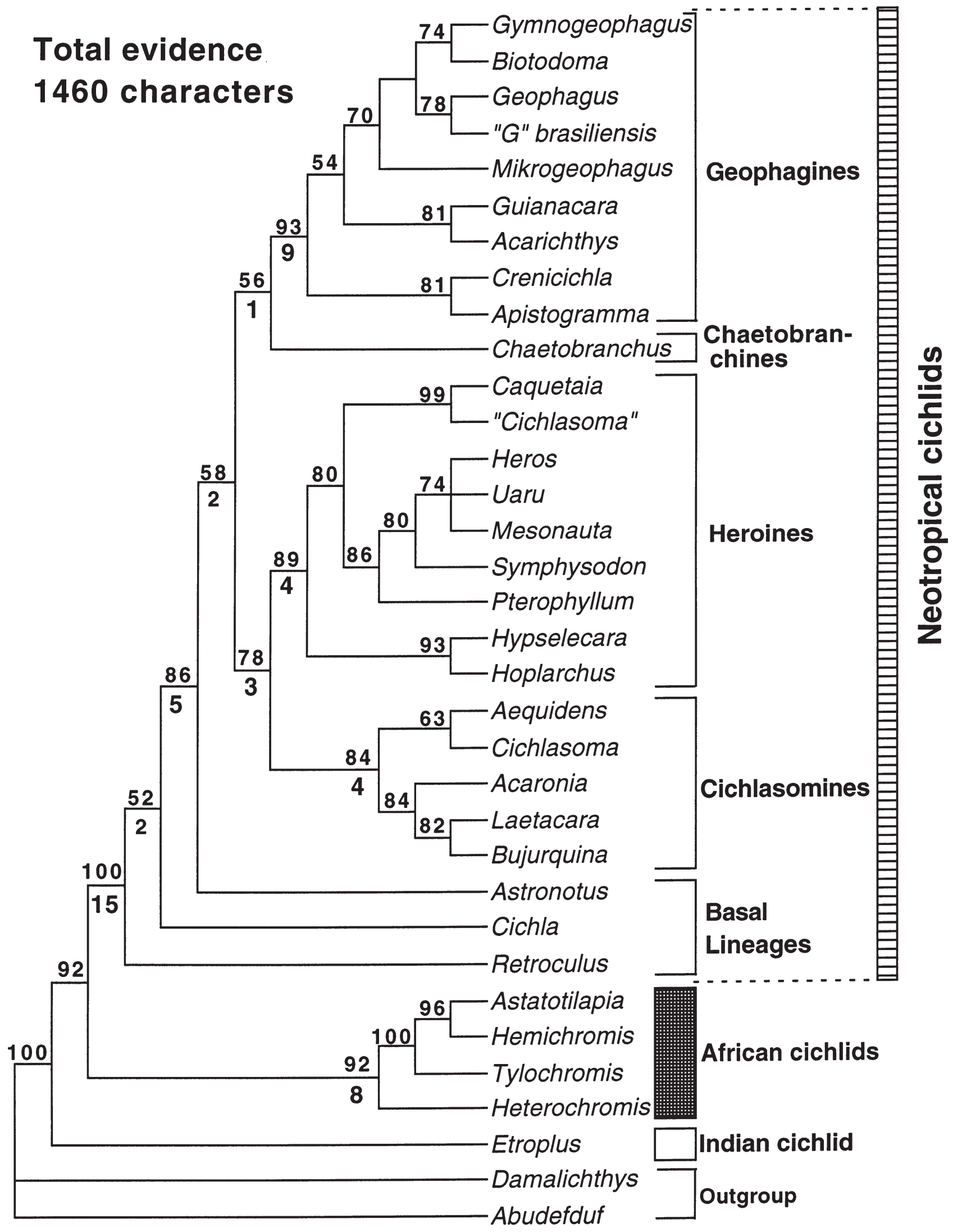

Figure 4. 


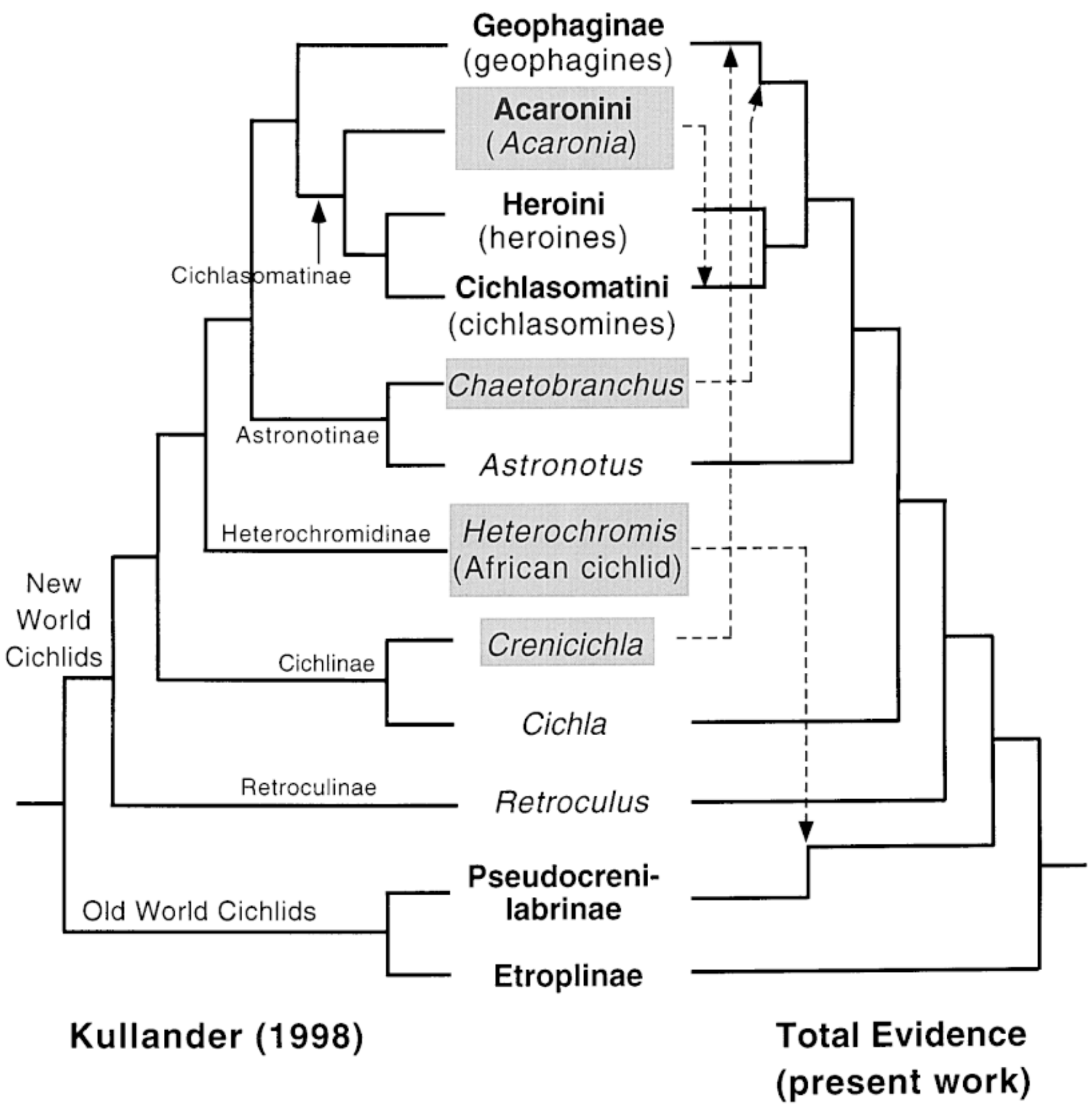

Fig. 5. Comparison among phylogenetic hypotheses from Kullander ('98) and the total evidence approach proposed in the present work.

Fig. 4. Strict consensus of three MP trees from Total Evidence $(16 \mathrm{~S}+$ nuclear loci + morphological data, 1,460 characters) $(\mathrm{L}=2,155, \mathrm{CI}=0.368, \mathrm{RI}=0.485)$. The numbers above branches are bootstrap values (only values above 50 are shown). The numbers below internodes correspond to branch support values. back mutation from a derived character state to an ancestral state). It remains to be seen if these three morphological characters have been influenced by such processes. Although it is well-known that molecular data are not free of homoplasy (CI values for our molecular data range from 0.37 to 0.51 ), the fact that three independent loci are phy- 
TABLE 2. Relative rate tests

\begin{tabular}{|c|c|c|c|c|c|}
\hline \multirow[b]{2}{*}{ Sequence } & \multicolumn{5}{|l|}{ Cluster } \\
\hline & $\mathrm{A} \times \mathrm{B}$ & $\mathrm{La}$ & $\mathrm{Lb}$ & $\delta$ & $\mathrm{Z}$ \\
\hline \multirow[t]{6}{*}{ 16S rRNA } & $\mathrm{La}=$ Neotropical $\times \mathrm{Lb}=$ African & 0.109 & 0.046 & 0.062 & $4.13^{*}$ \\
\hline & $\mathrm{La}=$ Neotropical (excluding geophagines $) \times \mathrm{Lb}=$ African & 0.088 & 0.051 & 0.036 & $2.56^{*}$ \\
\hline & $\mathrm{La}=$ Geophagines $\times \mathrm{Lb}=$ Rest Neotropical & 0.103 & 0.065 & 0.037 & $2.80 *$ \\
\hline & La $=$ River Afr $\times$ Lb $=$ Lake Afr cichlids & 0.062 & 0.031 & 0.030 & $2.85^{*}$ \\
\hline & La $=$ River Afr $\times$ Lb $=$ Neotropical cichlids & 0.111 & 0.073 & 0.037 & $2.18^{*}$ \\
\hline & $\mathrm{La}=$ River Afr $\times \mathrm{Lb}=$ Neotropical (excluding geophagine) & 0.083 & 0.070 & 0.013 & 0.85 \\
\hline \multirow[t]{2}{*}{ Tmo-M27 } & $\mathrm{La}=$ Neotropical $\times \mathrm{Lb}=$ African & 0.061 & 0.035 & 0.025 & 1.50 \\
\hline & $\mathrm{La}=$ Geophagines $\times \mathrm{Lb}=$ Rest Neotropical & 0.030 & 0.015 & 0.015 & $1.89^{\dagger}$ \\
\hline \multirow[t]{2}{*}{ Tmo-4C4 } & $\mathrm{La}=$ Neotropical $\times \mathrm{Lb}=$ African & 0.060 & 0.090 & 0.030 & 1.69 \\
\hline & $\mathrm{La}=$ Geophagines $\times \mathrm{Lb}=$ Rest Neotropical & 0.050 & 0.020 & 0.031 & $4.20 *$ \\
\hline \multirow{2}{*}{ Nuclear loci } & $\mathrm{La}=$ Neotropical $\times \mathrm{Lb}=$ African & 0.057 & 0.064 & 0.007 & 0.59 \\
\hline & $\mathrm{La}=$ Geophagines $\times \mathrm{Lb}=$ Rest Neotropical & 0.039 & 0.016 & 0.023 & $4.64 *$ \\
\hline
\end{tabular}

*Rate constancy is rejected at the $95 \%$ level.

†Value close to 1.96 required to reject the rate constancy at the 95\% level (Kumar, '96).

logenetically concordant argues against significant systematic bias in the DNA data (Swofford et al., '96) that could account for nonhistorical hierarchical signal (Naylor and Brown, '98).

Combining data is currently controversial and total evidence (character congruence) is only one of several methods that have been suggested (reviewed by Miyamoto and Fitch, '95). The total evidence analyses may be preferred not because it is more likely to find the unknowable "true" tree, however, rather because it searches, in a single hypothesis, to account for all of the relevant data within a parsimony framework (e.g., Kluge, '89).

\section{Rate comparison}

The basic idea of the relative-rate test is to compare distances between two lineages since they last shared a common ancestor. Increasing the number of ingroup sequences improves both accuracy and power of relative rate tests from a statistical point of view. According to Robinson et al. ('98) this is obtained by using as many distantly related ingroup sequences as possible, and by using the single nearest outgroup sequence alone. Thus, using a closely related outgroup makes the statistical test of rate constancy more powerful. Previously, we found rate heterogeneity among Neotropical and African cichlids using 16S rRNA sequences (Farias et al., '99). In the present study, by increasing the representation of African taxa, those results were confirmed. However, different rates between Neotropical and African taxa were significant only for the 16S rRNA mitochondrial gene. The relative rate test failed to find significant rate differences (Table 2) only when lacustrine cichlids in the African lineage and the
Neotropical geophagine lineage were excluded from the analysis. Tests applied to both mitochondrial and nuclear sequences confirmed that rate heterogeneity within the Neotropical clade is confined to the geophagine group. When applied to African cichlids alone (using Oxylapia as outgroup), only $16 \mathrm{~S}$ rRNA sequences showed significant rate heterogeneity among riverine and lacustrine African cichlids.

The amount of genetic variation within lineages may be an indication of their age, assuming more or less constant mutation rates and demography. High levels of genetic variation have been observed for mitochondrial genes in cichlids from Lake Tanganyika when compared to species flocks from Lake Malawi and Victoria (Meyer et al., '90; Sturmbauer and Meyer, '92). A similar observation was reported by Takahashi et al. ('98) using SINEs data, describing a relatively long basal branch for the common ancestor of the extant species of the Lamprologini, an endemic group of cichlids from Lake Tanganyika. Several studies have shown that the whole cichlid flock in Lake Tanganyika originated from a few ancient and genetically divergent lineages derived from riverine ancestors (Meyer, '93; Sturmbauer et al., '94; Nishida, '97; Takahashi et al., '98). Although representation of African taxa diversity is somewhat limited in our study, our results also support previous suggestions that the West African riverine cichlids are the basal lineages among African cichlids. Although highly speciose in lakes, cichlids in rivers seem likely to preserve a larger fraction of the total genetic variation represented in the family. Kullander ('98) suggested that riverine cichlid faunas are more likely to conserve ances- 
tral patterns of character distribution. Comparison of riverine cichlids from Africa and the Neotropics with their well-studied lacustrine relatives may help understand this pattern. Lamentably, their ecology, genetics, and evolution have been poorly characterized in contrast to that of cichlids from the Great African lakes (Greenwood, '91; Lowe-McConnell, '91; Mayer et al., '98).

The present results suggest that the rate of molecular evolution among Neotropical lineages may not be uniform. Rate heterogeneity can vary among phyletic lineages, genes, and gene regions within the same genome (Lopez et al., '97). Furthermore, rate heterogeneity among two lineages does not guarantee a molecular clock within each lineage (Robinson et al., '98). Differences in rates of molecular clocks might be related to body size, generation time, metabolic rate, DNA repair mechanisms and effective population size, and of course constraints on function of the gene product (Wu and Li, '85; Martin and Palumbi, '93; Moore, '95). Future work should test which of these hypotheses best explains the rate heterogeneity observed among Neotropical and African cichlids. We hope that our demonstration of rate heterogeneity among Neotropical cichlids may stimulate future studies correlating life history traits with rates and patterns of molecular evolution in cichlid fishes.

\section{ACKNOWLEDGMENTS}

We thank the many colleagues who provided tissue samples and species identification: A. Basolo, C. Silva, E. Feldberg, E. Ferreira, I. Koslowski, J. Alves-Gomes, J. Porto, J. Zuanon, M. Garcia, R. Reis, S. Kullander, T. Ploesch and W. Staeck. We thank T. Hrbek, W. Salzburger and members of the Ortí lab for providing useful comments on earlier versions of the manuscript. This work was supported in part by University of Nebraska-Lincoln (USA), Universidade Federal do Pará (Brazil), and Universidade do Amazonas (Brazil). IPF is a Ph.D. fellow from CAPES (Brazil). We also acknowledge support from the National Science Foundation (DEB-9615178), the Deutsche Forschungsgemeinschaft, the Fond der Chemischen Industrie, and University of Konstanz to A.M.

\section{LITERATURE CITED}

Ballard JWO, Thayer MK, Newton AF, Grismer ER. 1998. Data sets, partitions, and characters: philosophies and procedures for analyzing multiple data sets. Syst Biol 47:367-396.

Bremer K. 1988. The limits of amino acid sequence data in angiosperm phylogenetic reconstruction. Evolution 42:795-803.
Bremer K. 1994. Branch support and tree stability. Cladistics 10:295-304.

Bull JJ, Huelsenbeck P, Cunningham CW, Swofford DL, Waddell PJ. 1993. Partitioning and combining data in phylogenetic analysis. Syst Biol 42:384-397.

Cannatella DC, Hillis DM, Chippindale PT, Weigt L, Rand AS, Ryan MJ. 1998. Phylogeny of frogs of the Physalaemus pustulosus species group, with an examination of data incongruence. Syst Biol 47:311-335.

Chippindale PT, Wiens JJ. 1994. Weighting, partitioning, and combining characters in phylogenetic analysis. Syst Biol 43:278-287.

Cichoki F. 1976. Cladistic history of cichlid fishes and reproductive strategies of the American genera Acarichthys, Biotodoma, and Geophagus. Ph.D. thesis, University of Michigan, Ann Arbor.

Cunningham CW. 1997. Can tree incongruence tests predict when data should be combined? Mol Biol Evol 14:733-740.

de Queiroz A. 1993. For consensus (sometimes). Syst Biol 42:368-372.

de Queiroz A, Donoghue MJ, Kim J. 1996. Separate versus combined analysis of phylogenetic evidence. Annu Rev Ecol Syst 26:657-681.

Eernisse DJ, Kluge AG. 1993. Taxonomic congruence versus total evidence, and amniote phylogeny inferred from fossils, molecules, and morphology. Mol Biol Evol 10:1170-1195.

Farris JS. 1989. The retention index and rescaled consistency index. Cladistics 5:417-419.

Farris JS, Källersjö M, Kluge AG, Bult C. 1994. Testing significance of incongruence. Cladistics 10:315-319.

Farris JS, Källersjö M, Kluge AG, Bult C. 1995. Constructing a significance test for incongruence. Syst Biol 44:570-572.

Farias IP, Schneider H, Sampaio I. 1998. Molecular phylogeny of Neotropical cichlids: the relationships of cichlasomines and heroines. In: Malabarba LR, Reis RE, Vari RP, Lucena ZM, Lucena CAS, editors. Phylogeny and classification of Neotropical fishes. Porto Alegre, Brasil: Edipucrs. p 499-508.

Farias IP, Ortí G, Sampaio I, Schneider H, Meyer A. 1999. Mitochondrial DNA phylogeny of the family Cichlidae: monophyly and fast molecular evolution of the Neotropical assemblage. J Mol Evol 48:703-711.

Greenwood PH. 1991. Speciation. In: Keenleyside MHA, editor. Cichlid fishes-behavior, ecology, and evolution. London: Chapman and Hall. p 86-102.

Gu X, Fu Y-X, Li W-H. 1995. Maximum likelihood estimation of the heterogeneity of substitution rate among nucleotide sites. Mol Biol Evol 12:546-557.

Hasegawa M, Kishino H, Yano T. 1985. Dating of the human-ape splitting by a molecular clock of mitochondrial DNA. J Mol Evol 22:160-174.

Huelsenbeck JP, Bull JJ, Cunningham CW. 1996. Combining data in phylogenetic analysis. TREE 11:152-158.

Keenleyside MHA, editor. 1991. Cichlid Fishes-behavior, ecology, and evolution. London: Chapman and Hall.

Kidd KK, Sgaramella-Zonta LA. 1971. Phylogenetic analysis: concepts and methods. Am J Hum Genet 23:235-252.

Kluge AG. 1989. A concern for evidence and a phylogenetic hypothesis of relationships among Epicrates (Boidae, Serpentes). Syst Zool 38:7-25.

Kluge AG. 1998. Total evidence or taxonomic congruence: Cladistics or consensus classification. Cladistics 14:151-158.

Kluge AG, Farris JS. 1969. Quantitative phyletics and the evolution of anurans. Syst Zool 18:1-32. 
Kullander SO. 1983. A revision of the South American cichlid genus Cichlasoma. Stockholm: Swedish Museum of Natural History.

Kullander SO 1998. A phylogeny and classification of the South American Cichlidae (Teleostei: Perciformes). In: Malabarba LR, Reis RE, Vari RP, Lucena ZM, Lucena CAS, editors. Phylogeny and classification of Neotropical fishes. Porto Alegre, Brasil: Edipucrs. p 461-498.

Kumar S. 1996. PHYLTEST: phylogeny hypothesis testing software. University Park: Pennsylvania State University.

Liu FR, Miyamoto MM. 1999. Phylogenetic assessment of molecular and morphological data for eutherian mammals. Syst Biol 48:54-64.

Lopez JV, Culver M, Stephens C, Johnson WE, O'Brien SJ. 1997. Rates of nuclear and cytoplasmic mitochondrial DNA sequence divergence in mammals. Mol Biol Evol 14:277-286.

Lowe-McConnell RH. 1991. Ecology of cichlids in South American and African waters, excluding the African Great Lakes. In: Keenleyside MHA, editor. Cichlid fishes-behavior, ecology, and evolution. London: Chapman and Hall. p 60-85.

Maddison WP, Maddison DR. 1992. MacClade: analysis of phylogeny and character evolution, version 3.0. Sunderland, MA: Sinauer.

Martin AP, Bermingham E. 1998. Systematics and evolution of lower Central American cichlids inferred from analysis of cytochrome $b$ gene sequence. Mol Phylogenet Evol 9:192-203.

Martin AP, Palumbi SR. 1993. Body size, metabolic rate, generation time, and the molecular clock. Proc Natl Acad Sci USA 90:4087-4091.

Mayer WE, Tichy H, Klein J. 1998. Phylogeny of African cichlid fishes as revealed by molecular markers. Heredity 80:702-714

Meyer A. 1993. Phylogenetic relationships and evolutionary processes in East African cichlid fishes. Trend Ecol Evol 8:279-284.

Meyer A. 1999. Homology and homoplasy: the retention of genetic programmes. In: Novatis Foundation Symposium 222. Homology. England: John Wiley \& Sons Ltd. p 141-157.

Meyer A, Kocher TD, Basasibwaki P, Wilson AC. 1990. Monophyletic origin of Lake Victoria cichlid fishes suggested by mitochondrial DNA sequences. Nature Lond 347:550-553.

Miyamoto MM, Fitch WM. 1995. Testing species phylogenies and phylogenetic methods with congruence. Syst Biol 44:64-76.

Moore WS. 1995. Inferring phylogenies from mtDNA variation: mitochondrial-gene trees versus nuclear-gene trees. Evolution 49:718-726.

Naylor GJP, Brown WM. 1998. Amphioxus mitochondrial DNA, chordate phylogeny, and the limits of inference based on comparisons of sequences. Syst Biol 47: 61-76.

Nishida M. 1997. Phylogenetic relationships and evolution of tanganyikan cichlids: a molecular perspective. In: Kawanabe H, Hori M, Nagoshi M, editors. Fish communities in Lake Tanganyika. Kyoto, Japan: Kyoto University Press. p 1-23.

Palumbi S, Martin A, Romano S, McMillian WO, Stice L, Grabowski G. 1991. The simple fool's guide to PCR. Honolulu: University of Hawaii.

Penny D, Hendy MD. 1986. Estimating the reliability of evolutionary trees. Mol Biol Evol 3:403-417.

Quicke DLJ, Belshaw R. 1999. Incongruence between morphological data sets: an example from the evolution of endoparasitism among parasitic wasps (Hymenoptera: Braconidae). Syst Biol 48:436-454.

Robinson M, Gouy M, Gautier C, Mouchiroud D. 1998. Sen- sitivity of the relative -rate test to taxonomic sampling. Mol Biol Evol 15:1091-1098.

Rodrigo AG, Kelly-Borges M, Bergquist PR, Bergquist PL. 1993. A randomization test of the null hypothesis that two cladograms are sample estimates of a parametric phylogenetic tree. N Z J Bot 31:257-268.

Roe KL, Conkel D, Lydeard C. 1997. Molecular systematic of Middle American cichlid fishes and evolution of trophic-types in 'Cichlasoma (Amphilophus)' and 'C. (Thorichthys)'. Mol Phylogenet Evol 7:366-376.

Sambrook J, Fritsch EF, Maniatis T. 1989. Molecular cloning: a laboratory manual, 2nd ed. New York: Cold Spring Harbor Laboratory Press.

Schmidt W and ag editorial team. 1996. La grandle Ile. Aqua Geographia 13:5-36.

Stiassny MLJ. 1981. The phyletic status of the family Cichlidae (Pisces: Perciformes): a comparative anatomical investigation. Neth J Zool 31:275-314.

Stiassny MLJ. 1991. Phylogenetic intrarelationships of the family Cichlidae. In: Keenleyside MHA, editor. Cichlid fishes-behavior, ecology, and evolution. London: Chapman and Hall. p 1-31.

Stiassny MLJ. 1992. Atavism, phylogenetic character reversals, and the origin of evolutionary novelties. Neth J Zool 42:260-276.

Stiassny MLJ, Meyer A. 1999. Cichlids of rift lakes. Sci Am 280:64-69.

Streelman JT, Karl SA. 1997. Reconstructing labroid evolution with single-copy nuclear DNA. Proc R Soc Lond B 264:1011-1020.

Streelman JT, Zardoya R, Meyer A, Karl SA. 1998. Multilocus phylogeny of cichlid fishes (Pisces: Perciformes): evolutionary comparison of microsatellite and single-copy nuclear loci. Mol Biol Evol 15:798-808.

Sturmbauer C. 1998. Explosive speciation in cichlid fishes of the African Great Lakes: a dynamic model of adaptive radiation. J Fish Biol 53:18-36.

Sturmbauer C, Meyer A. 1992. Genetic divergence, speciation and morphological stasis in a lineage of African cichlid fishes. Nature Lond 359:578-581.

Sturmbauer C, Verheyen E, Meyer A. 1994. Mitochondrial phylogeny of the Lamprologini, the major substrate spawning lineage of cichlid fishes from Lake Tanganyika in Eastern Africa. Mol Biol Evol 11:691-703.

Sullivan J 1996. Combining data with different distributions of among-site variations. Syst Biol 45:375-380.

Sültmann H, Mayer WE, Figueroa F, Tichy H, Klein J. 1995. Phylogenetic analysis of cichlid fishes using nuclear DNA markers. Mol Biol Evol 12:1033-1047.

Swofford DL. 1991. When are phylogeny estimates from molecular and morphological data incongruent? In: Miyamoto MM, Cracraft J, editors. Phylogenetic analysis of DNA sequences. New York: Oxford University Press. p 295-333.

Swofford DL. 1998. PAUP* Phylogenetic analysis using parsimony and other methods, Version 4.0b. Sunderland, MA: Sinauer.

Swofford DL, Olsen GJ, Waddell PJ, Hillis DM. 1996. Phylogenetic inference. In: Hillis DM, Moritz C, Mable BK, editors. Molecular Systematics. Second edition. Sunderland, MA: Sinauer. p 407-514.

Takahashi K, Terai Y, Nishida M, Okada N. 1998. A novel family of Short Interspersed Repetitive Elements (SINEs) from cichlids: the patterns of insertion of SINEs at orthologous loci support the proposed monophyly of four major 
groups of cichlid fishes in Lake Tanganyika. Mol Biol Evol 15:391-407.

Takezaki N, Rzhetsky A, Nei M. 1995. Phylogenetic test of the molecular clock and linearized trees. Mol Biol Evol 12:823-833.

Thompson JD, Higgins DG, Gibson TJ. 1994. CLUSTAL W: improving the sensitivity of progressive multiple sequence alignment through sequence weighting, position specific gap penalties, and weight matrix choice. Nucleic Acids Res 22:4673-4680.

Wiens JJ. 1998. Combining data sets with different phylogenetic histories. Syst Biol 47:568-581.
Wu CI, Li WH. 1985. Evidence for higher rates of nucleotide substitution in rodents than in man. Proc Natl Acad Sci USA 82:1741-1745.

Yang Z. 1993. Maximum likelihood estimation of phylogeny from DNA sequences when substitution rates differ over sites. Mol Biol Evol 10:1396-1401.

Zardoya R, Vollmer DM, Craddock C, Streelman JT, Karl SA, Meyer A. 1996. Evolutionary conservation of microsatellite flanking regions and their use in resolving the phylogeny of cichlid fishes (Pisces: Perciformes). Proc R Soc Lond B 263:1589-1598.

APPENDIX. Taxa of fishes included in this study ${ }^{1}$

\begin{tabular}{|c|c|c|c|}
\hline Taxa & 16S rRNA & Tmo-M27 & Tmo-4C4 \\
\hline \multicolumn{4}{|l|}{ Embiotocidae } \\
\hline Cymatogaster aggregata & 3 & - & - \\
\hline Damalichthys vacca & 4 & 1 & 2 \\
\hline \multicolumn{4}{|l|}{ Pomacentridae } \\
\hline Abudefduf saxatilis & 3 & 1 & 2 \\
\hline \multicolumn{4}{|l|}{ Cichlidae } \\
\hline \multicolumn{4}{|l|}{ Etroplinae (Malagasy and India) } \\
\hline Etroplus maculatus & 3 & 1 & 2 \\
\hline Oxylapia polleni & 3 & - & - \\
\hline Paretroplus polyactis & 3 & 1 & 2 \\
\hline Ptychochromoides betsileanus & 3 & - & - \\
\hline Ptychochromis oligocantus & 3 & - & - \\
\hline \multicolumn{4}{|l|}{ Pseudocrenilabrinae (Africa) } \\
\hline Astatoreochromis alluaudi & 4 & 1 & 2 \\
\hline Astatotilapia callipitera & 4 & 1 & 2 \\
\hline Boulengerochromis microlepis & 3 & 1 & 2 \\
\hline Chalinochromis brichardi & 3 & - & - \\
\hline Chromidotilapia sp. & 3 & - & - \\
\hline Haplochromis sp. & 3 & - & - \\
\hline Hemichromis bimaculatus & 3 & 1 & 2 \\
\hline Labidochromis caeruleus & 4 & 1 & 2 \\
\hline Melanochromis sp. & 4 & - & - \\
\hline Oreochromis niloticus & 3 & - & - \\
\hline Pelvicachromis pulcher & - & 1 & 2 \\
\hline Serranochromis robustus & 3 & 1 & 2 \\
\hline Thysochromis sp. & 3 & - & - \\
\hline Tilapia sp. & 3 & - & - \\
\hline Tropheus moorii & 4 & 1 & 2 \\
\hline Tylochromis polylepis & 4 & 1 & 2 \\
\hline \multicolumn{4}{|l|}{ Heterochromidinae (Africa) } \\
\hline Heterochromis multidens & 3 & 4 & 4 \\
\hline \multicolumn{4}{|l|}{ Retroculinae (South Africa) } \\
\hline Retroculus sp. & 3 & 4 & 4 \\
\hline Retroculus xinguensis & 3 & 4 & 4 \\
\hline \multicolumn{4}{|l|}{ Cichlinae (South America) } \\
\hline \multicolumn{4}{|l|}{ Cichlini } \\
\hline Cichla sp. & 4 & 4 & 4 \\
\hline Cichla monoculus & 3 & - & - \\
\hline Cichla orinocensis & 3 & 4 & 4 \\
\hline Cichla temensis & 3 & - & - \\
\hline \multicolumn{4}{|l|}{ Crenicichlini } \\
\hline Crenicichla sp. & 3 & - & - \\
\hline Crenicichla lugubris & 3 & - & - \\
\hline Crencichla regani & 3 & 4 & 4 \\
\hline Teleocichla centrarchus & 3 & 4 & 4 \\
\hline Teleocichla cinderella & 3 & - & - \\
\hline
\end{tabular}


Astronotinae (South America)

Astronotini

Astronotus crassipinnis

Astronotus ocellatus

Chaetobranchini

Chaetobranchopsis orbicularis

Chaetobranchus flavescens

Chaetobranchus semifasciatus

Geophaginae (South America)

Acarichthyini

Acarichthys heckelii

Guianacara sp.

Crenicaritini

Biotoecus sp.

Crenicara sp.

Geophagini

Apistogramma sp. 1

Apistogramma sp. 2

Biotodoma wavrini

Geophagus sp.

Geophagus altifrons

Geophagus argyrostictus

Geophagus proximus

'Geophagus' brasiliensis

Gymnogeophagus gymnogenys

Gymnogeophagus labiatus

Mikrogeophagus altispinosus

Satanoperca acuticeps

Satanoperca jurupari

Taeniacara candidi

3

3

$-$

3

3

3

4

$-$

3

4

Cichlasomatinae (South America)

Acaroniini (South America)

Acaronia sp.

Acaronia nassa

3

Cichlasomatini (South America)

Aequidens michaeli

'Aequidens'sp.

Bujurquina sp.

Cichlasoma amazonarum

Laetacara curviceps

Nannacara sp.

Heroini (South America)

Caquetaia spectabilis

Heros sp.

Hoplarchus psittacus

Hypselecara coryphaenoides

Mesonauta insignis

Pterophyllum scalare

Symphysodon aequifasciatus

Uaru amphiacanthoides

Heroini (Central America)

'Cichlasoma' octofasciatum

Petenia splendida

Amphilophus citrinellu

Archocentrus nigrofasciatus

${ }^{1}$ Taxonomy follows Kullander ('98). Genera between quotation marks are not valid for the species indicated (e.g., 'Aequidens,' 'Geophagus,' 'Cichlasoma') but are used for lack of a better name. Voucher specimen and locality information is available from I.P.F. Numbers identify the source of the sequence data analyzed in the present paper. 1: Tmo-M27 data from Zardoya et al. ('96); 2: Tmo-4C4 data from Streelman and Karl ('97); 3: 16S rRNA data from Farias et al. ('99); 4: new data determined in present study. 